\title{
ANALISA BUNDARAN TUGU KERIS SIGINJAI KOTA BARU JAMBI
}

\author{
Muhammad Zuchri Hsb, Eri Dahlan \\ Program Studi Teknik Sipil Universitas Batanghari \\ mccjbi@gmail.com
}

\begin{abstract}
Abstrak
Bundaran Tugu Keris Siginjai Kota Baru merupakan salah satu bundaran yang ada di Kota Jambi. Bundaran ini melayani arus lalu lintas yang berasal dari Jalan Jendral Basuki Rahmat, Jalan Haji Agus Salim, Jalan H. Zainir Havis. Bundaran Tugu Keris Siginjai Kota Baru merupakan bundaran penting dan mempunyai arus lalu lintas yang ramai pada jam - jam tertentu karena letak bundaran yang berada di sektor perkantoran, pendidikan dan rekreasi. Data yang digunakan pada penelitian ini yaitu data primer dan skunder.Dalam melakukan analisa, perhitungan yang dilakukan peneliti berdasarkan pada Metode Manual Kapasitas Jalan Indonesia (MKJI) 1997.Adapun tujuan dilakukannya penelitian ini adalah untuk mengetahui kapasitas dan kinerja bundaran saat ini terhadap kondisi lalu lintas yang ada. Selain itu peneliti juga ingin mengetahui berapa lama waktu tundaan yang terjadi di Bundaran tersebut. Dari hasil analisis diketahui kapasitas pada bagian jalinan $\mathrm{AB}=3571$, jalinan $\mathrm{BC}=3516$, jalinan $\mathrm{CD}=3540$, dan jalinan DA $=3579$. Nilai tundaan bundaran (DR) pada Bundaran Tugu Keris Siginjai Kota Baru Jambi yaitu 4,49 det/smp, dengan demikian tundaan dianggap tidak ada karena $\mathrm{D}<10$ detik.

Kata Kunci: bundaran, kapasitas, kinerja
\end{abstract}

\section{PENDAHULUAN}

Jalan raya merupakan prasarana transportasi yang paling besar pengaruhnya terhadap perkembangan sosial dan ekonomi masyarakat. Fungsi utama jalan raya adalah sebagai prasarana untuk melayani pergerakan manusia dan barang secara aman, nyaman, cepat dan ekonomis.

Bundaran Tugu Keris Siginjai Kota Baru Jambi merupakan simpang tak bersinyal pertemuan jalan yang melayani arus lalu lintas yang berasal dari Jalan Jendral Basuki Rahmat, Jalan Haji Agus Salim, Jalan H. Zainir Havis.

Bundaran Tugu Keris Siginjai Kota Baru Jambi merupakan salah satu bundaran penting dan mempunyai arus lalu lintas yang ramai pada jam - jam tertentu karena letak bundaran yang berada disektor perkantoran, pendidikan dan rekreasi. Adapun jenis kendaran yang biasa melewati jalan ini yaitu : sepeda, sepeda motor, dan kendaraan ringan.

Dari pengamatan di lapangan, kendaraan yang melintas di Bundaran Tugu Keris Siginjai Kota Baru Jambi semakin meningkat. Karena meningkatnya jumlah kendaraan yang melintas di Bundaran Tugu Keris Siginjai Kota Baru Jambi ini sering pula terjadi tundaan kendaraan di bundaran tersebut terutama pada jam jam sibuk. Oleh Karena itu peneliti ingin mengetahui seberapa besar permasalahan yang ada di Bundaran Tugu Keris Siginjai Kota Baru Jambi akibat adanya tundaan kendaran tersebut, selain itu peneliti juga ingin mengetahui kinerja Bundaran Tugu Keris Siginjai Kota Baru Jambi terhadap kondisi lalu lintas saat ini berdasarkan metode Manual Kapasitas Jalan Indonesia (MKJI) 1997 demi kenyamanan dan kelancaran pengguna jalan. 


\section{LANDASAN TEORI \\ Konsep Dasar Bundaran}

Bundaran (round-about) merupakan salah satu jenis pengendalian persimpangan yang umumnya dipergunakan pada daerah perkotaan dan luar kota. Lalu lintas yang didahulukan adalah lalu lintas yang sudah berada dibundaran, sehingga kendaraan yang akan masuk ke bundaran harus memberikan kesempatan terlebih dahulu kepada lalu lintas yang sudah berada di bundaran.

Bagian jalinan dibagi menjadi dua tipe yitu bagian jalinan tunggal dan bagian jalinan bundaran. Bagian jalinan tunggal adalah bagian jalinan jalan antara dua pergerakan lalu lintas yang menyatu dan memancar sedangkan bagian jalinan bundaran adalah bagian jalinan pada bundaran ( MKJI 1997 ).

(B)

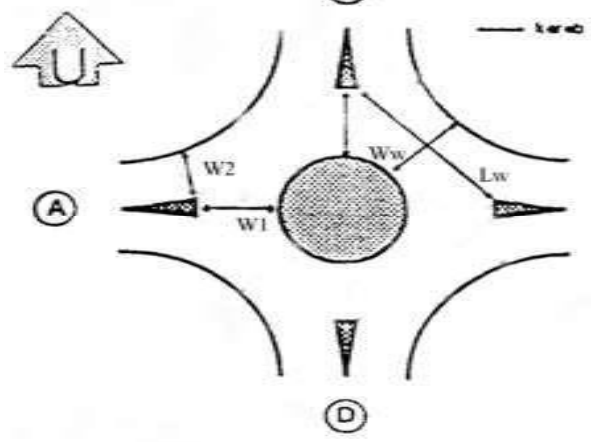

Bagian Jalinan Tunggal

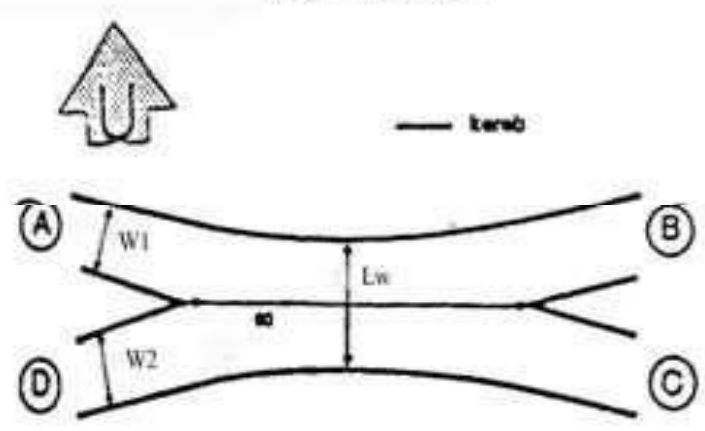

Gambar1. Bagian Jalinan Tunggal dan Bundaran

Sumber : MKJI 1997

Keterangan :

$\mathrm{W} 1=$ Lebar pendekat 1 yang akan masuk kebagian jalan.

$\mathrm{W} 2=$ Lebar pendekat 2 yang akan masuk kebagian jalinan.

$\mathrm{LW}=$ panjang jalinan.

$\mathrm{Ww}=$ Lebar jalinan.

$\mathrm{We}=$ Lebar rata - rata pendekat untuk masing - masing bagian jalinan.

\section{Kapasitas}

Kapasitas bundaran dapat diprediksi dengan menggunakan hubungan antara aliran masuk dan beredar ( R. J. Salter 1981 ). Kapasitas total bagian jalinan adalah hasil perkiraan antara kapasitas dasar ( C ) yaitu kapasitas pada kondisi tertentu ( ideal ) dan faktor penyesuaian ( F ), dengan memperhitungkan pengaruh kondisi lapagan sesungguhnya terhadap kapasitas. Model kapasitas adalah sebagai berikut :

$\mathrm{C}_{\mathrm{O}}=135 \times \mathrm{WW}_{\mathrm{W}}^{1,3} \times\left(1+\mathrm{W}_{\mathrm{F}} / \mathrm{WW}_{\mathrm{W}}\right)^{1,5} \times\left(1-\mathrm{PW}_{\mathrm{W}} / 3\right)^{0,5} \mathrm{x}\left(1+\mathrm{WW}_{\mathrm{W}} / \mathrm{LW}\right)^{-1,8} \times$ Fcs $\mathrm{x}$ FRsu

Dimana :

$\mathrm{WE} \quad=$ Lebar Masuk Rata - Rata

$\mathrm{WW}=$ Lebar Jalinan $(\mathrm{m})$

$\mathrm{L}_{\mathrm{W}} \quad=\quad$ Panjang Jalinan $(\mathrm{m})$

$\mathrm{PW}=$ Rasio Jalinan $=(\mathrm{QW} / \mathrm{Qtot})$

QW $=$ Arus Menjalin $(\mathrm{smp} / \mathrm{jam})$

Qtot $=$ Arus Total $(\mathrm{smp} / \mathrm{jam})$

FCS $=$ Faktor Penyesuaian Ukuran 
FRSU = Faktor Penyesuaian Tipe Lingkungan

\section{Derajat Kejenuhan}

Prilaku lalu lintas bagian jalinan berkaitan erat dengan derajat kejenuhan. Menurut Manual Kapasitas Jalan Indonesia ( MKJI ) 1997, derajat kejenuhan (DS) bagian jalinan dapat dihitung dengan rumus sebagai berikut:

$$
\begin{aligned}
& \mathrm{DS}=\frac{Q}{C} \\
& Q_{\text {smp }}=Q_{\text {kendaraan }} x Q_{\text {smp }} \\
& F_{s m p}=\frac{L v \%+\left(H_{V} \% \times e m p_{H V}\right)+\left(M_{C} \% \times e m p_{M C}\right)}{100}
\end{aligned}
$$

\section{Tundaan Pada Bagian Jalinan Bundaran}

Tundaan lalu lintas bagian jalinan (DT), menurut MKJI 1997 tundaan lalu lintas ditentukan dari hubungan empiris antara tundaan lalu lintas dan derajat kejenuhan. Tundaan lalu lintas ditentukan dari hubungan antara tundaan lalu lintas dan derajat kejenuhan. Tundaan rata - rata bagian jalinan dapat dihitung sebagai berikut :

$\mathrm{D}=\mathrm{DT}+\mathrm{DG}$

Dimana :

D $\quad=$ Tundaan Rata - Rata Bagian Jalinan ( det / smp )

DT $\quad=$ Tundaan Lalu Lintas Rata - Rata Bagian Jalinan ( det / smp )

DG = Tundaan Geometrik Rata - Rata Bagian Jalinan $(\operatorname{det} / \mathrm{smp})$

Tundaan geometrik pada bagian jalinan ditentukan sebagai berikut :

Tundaan lalu lintas bundaran (DTR) tundaan rata - rata perkendaraan yang masuk kedalam bundaran dapat dihitung dengan rumus berikut :

$\mathrm{DTR}=\frac{\sum(\text { Qix DTi })}{\text { Qmasuk }}+\mathrm{DG} ; \mathrm{I}=1 \ldots \mathrm{n}$

Dimana :

I $=$ Bagian Jalinan I Dalam Bundaran.

$\mathrm{n}=$ Jumlah Bagian Jalinan Dalam Bundaran.

Qi $\quad=$ Arus Total Pada Bagian Jalinan i ( smp / jam )

$\mathrm{DT}_{\mathrm{i}} \quad=$ Tundaan Arus Lalu Lintas Pada Bagian Jalinan i ( smp / jam $)$

Qmasuk = Jumlah Arus Yang Masuk Bundaran ( smp / jam )

DG = Tundaan Rata - Rata Geometrik Pada Bagian Jalinan ( $\mathrm{smp} / \mathrm{jam})$

Tundaan bundaran ( DR ) adalahtundaan lalulintas rata - rata per kendaraan masuk bundaran dan dihitung dengan rumus sebagai berikut:

$\mathrm{DR}=\mathrm{DTR}+4$

Pada perhitungan ini adalah menambahkan tundaan geometrik rata rata ( 4 det / smp ) pada tundaan lalu lintas. Jika besar tundaan yang dihasilkan lebih kecil dari 10 detik ( $\mathrm{D}<10$ det ) maka bundaran ini tidak terjadi tundaan. 


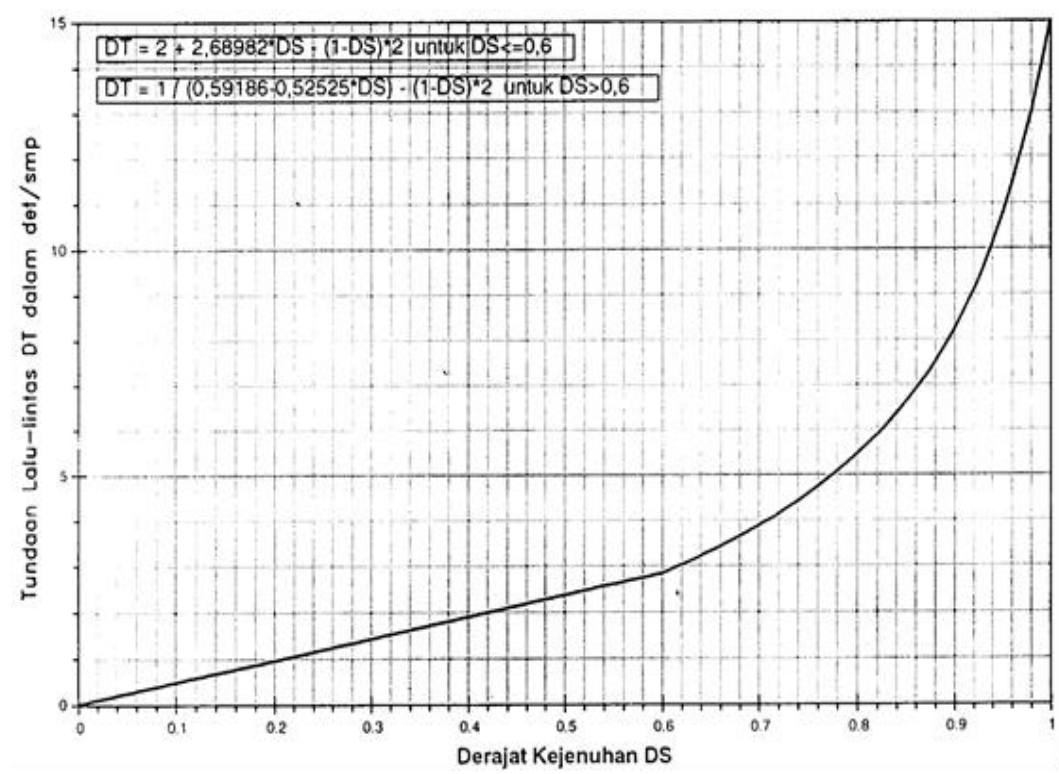

Gambar 2 Grafik Tundaan Lalu Lintas Bagian Jalinan vs Derajat Kejenuhan. Sumber : MKJI 1997

\section{Peluang Antrian Pada Bagian Jalinan Bundaran}

Menurut MKJI 1997 peluang antrian dihitung dari hubungan empiris antara peluang antrian dengan derajat kejenuhan. Peluang antrian pada bundaran ditentukan dengan rumus berikut :

Batas atas $\mathrm{QP}=26,65 \times \mathrm{DS}-55,55 \times \mathrm{DS}^{2}+108,7 \mathrm{DS}^{3}$

Batas bawah QP $=9,41 \times$ DS + 29,967x DS 4,619

Peluang antrian bundaran ditentukan dari nilai :

$$
\mathrm{QPR} \%=\text { maks.dari }\left(\mathrm{QP}_{\mathrm{i}} \%\right) ; \mathrm{i}=\mathrm{n}
$$

Dimana :

Qpi = Peluang antrian jalinan.

$\mathrm{QPR} \quad=$ Peluang antrian bundaran $(\%)$.

$\mathrm{N}=$ Jumlah bagian jalinan dalam bundaran.

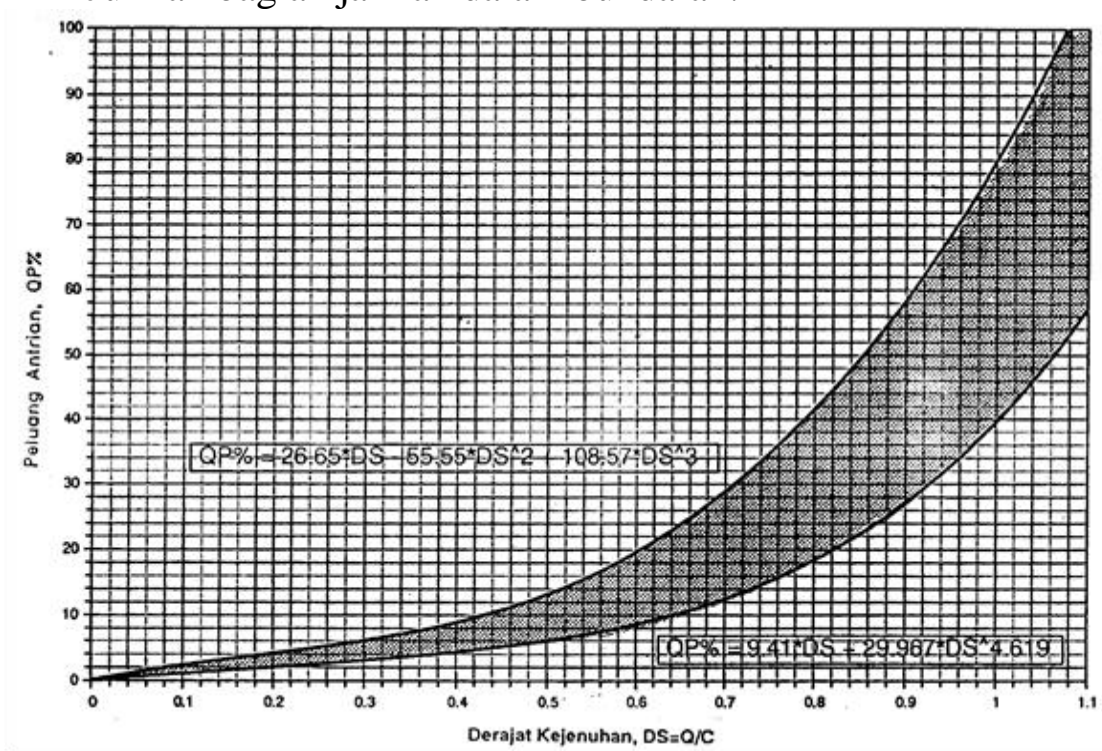

Gambar 3 Grafik peluang antrian vs derajat kejenuhan Sumber : MKJI 1997 


\section{METODE PENELITIAN}

Dalam menyelesaikan penelitian ini metode yang digunakan adalah metode observasi yaitu pengamatan dan pencatatan secara langsung di lapangan.Observasi ini lebih menekankan pada pengambilan data di lapangan secara langsung selama tiga hari. Data yang diperlukan baik berupa data primer maupun sekunder.

Data primer yaitu data yang diperoleh dari hasil penelitian langsung di lapangan, sedangkan data sekunder adalah data yang diperoleh dari instansi yangterkait.

Data yang diambil di lapangan adalah:

a. Kondisi geometrik

Diameter bundaran

1) Lebar pendekat $W_{1}$ dan $W_{2}$

2) Lebar jalinan $\mathrm{Ww}$

3) Panjang jalinan Lw

4) Lebar Jalan

b. Volume lalu lintas

Data arus lalu lintas berupa banyaknya kendaran yang melewati Bundaran Tugu Keris Siginjai Kota Baru Jambi yaitu :

a. kendaran berat.

b. kendaran ringan.

c. sepeda motor.

d. kendaran tidak bermotor.

Adapun cara pelaksanaan pengamatan dilakukan sebagai berikut :

1. Perhitungan dilakukan untuk setiap interval waktu 15 menit.

2. Perhitungan dilakukan oleh \pm 16 surveyor.

3. Hasil perhitungan dicatat pada formulir yang telah disediakan.

\section{HASIL DAN PEMBAHASAN}

Dari hasil survey yang dilakukan selama tiga hari yaitu pada hari senin, selasa, dan sabtu data LHR di Bundaran Tugu Keris Siginjai Kota Baru Jambi. Data yang digunakan untuk perhitungan yaitu data LHR terpadat yang kemudian dijadikan dalam satuan smp/jam.

\section{Perhitungan Arus Masuk Bagian Jalinan}

Arus masuk bagian jalinan adalah arus lalu lintas dari lengan pendekat yang masuk pada bagian jalinan bundaran. Perhitungannya dapat dilihat pada tabel dibawah ini :

Tabel 1 Perhitungan Arus Masuk Bagian Jalinan

\begin{tabular}{clc}
\hline Bagian Jalinan & Arus Masuk (smp/jam) & Q (smp/jam) \\
\hline \multirow{2}{*}{ AB } & QA + QD.ST + QD.RT + QC.RT & 13496 \\
& $13143+63+198+92$ & \\
BC & QB + QA.ST +QA.RT + QD.RT & 4943 \\
& $3683+447+615+198$ & \\
CD & QC + QB.ST + QB.RT + QA.RT & 8571 \\
& $7708+180+68+615$ & \\
DA & QD + QD.ST + QC.RT + QB.RT & 9841 \\
\hline
\end{tabular}

(Sumber:Analisis Data Primer) 
Dari hasil perhitungan arus masuk bagian jalinan maka di dapat arus masuk bundaran, yaitu :

Arus masuk bundaran $=13496+4943+8571+9841=36851 \mathrm{smp} / \mathrm{jam}$

\section{Perhitungan Arus Menjalin (Qw)}

Hasil perhitungan arus menjalin bagian jalinan dapat dilihat pada tabel dibawah ini :

Tabel 2 Perhitungan Arus Menjalin

\begin{tabular}{clc}
\hline Bagian Jalinan & Arus Masuk (smp/jam) & Qw (smp/jam) \\
\hline \multirow{2}{*}{ AB } & QA.ST+ QA.RT + QD.ST + QC.RT & 1217 \\
& $447+615+63+92$ & \\
BC & QB.ST + QB.RT +QA.ST + QD.RT & 893 \\
& $180+68+447+198$ \\
CD & QC.ST + QC.RT + QB.RT + QA.RT & \\
& $439+92+68+615$ & 1214 \\
DA & QD.ST + QD.RT + QC.ST + QB.RT & 768 \\
& $63+198+439+68$ & \\
\hline
\end{tabular}

(Sumber: Analisis Data Primer)

Dari hasil perhitungan arus masuk bagian jalinan dan perhitungan arus menjalin $(\mathrm{Qw})$ maka akan didapat rasio menjalin $(\mathrm{Pw})$. Rasio menjalin adalah perbandingan antara arus menjalin dengan arus bagian jalinan, perhitungannya sebagai berikut :

a) $\left.\mathrm{Pw} \mathrm{AB}=\frac{1217}{13496}=0,09 b\right)$. $\mathrm{Pw} \mathrm{BC}=\frac{893}{4943}=0,18$

b) $\left.\mathrm{Pw} C D=\frac{1214}{8571}=0,141 \mathrm{~d}\right)$. Pw DA $=\frac{768}{9841}=0,078$

\section{Kondisi Lingkungan}

a) Faktor penyesuaian ukuran kota

Berdasarkan data dari Badan Pusat Statistik (BPS), jumlah penduduk Kota Jambi pada tahun 2016 adalah sebanyak 583.487 jiwa. Dari data tersebut diketahui bahwa ukuran Kota Jambi adalah sedang, maka faktor penyesuaian ukuran kota (Fcs) adalah 0,94. (MKJI 1997)

b) Faktor penyesuaian tipe lingkungan jalan, hambatan samping dan kendaraan tak bermotor (PUM) dengan jenis lingkugan dikategorikan permukiman. Berikut perhitungan rasio kendaraan tak bermotor :

$$
\begin{aligned}
& \text { PUMA }=\frac{14}{19119}=0,00073 \text { PUMB }=\frac{0}{5705}=0 \\
& \text { PUMC }=\frac{3}{11870}=0,00025 \text { PUMD }=\frac{1}{14422}=0,00007
\end{aligned}
$$

Dari hasil perhitungan tersebut diketahui hambatan samping dikategorikan rendah. Maka faktor penyesuaian tipe lingkungan, hambatan samping dan rasio kendaraan tak bermotor (FRSU) dapat dilihat pada tabel berikut : 
Tabel 3 Penyesuaian Tipe Lingkungan, Hambatan Samping Dan Rasio Kendaraan Tak Bermotor (FRSU)

\begin{tabular}{lccc}
\hline \multicolumn{1}{c}{ Lengan Pendekat } & FCS & PUM & FRSU \\
\hline A (selatan) & 0,94 & 0,00073 & 0,98 \\
B (Barat) & 0,94 & 0 & 0,98 \\
C (Utara) & 0,94 & 0,00025 & 0,98 \\
D (Timur) & 0,94 & 0,00007 & 0,98 \\
\hline
\end{tabular}

(Sumber: Analisis Data Primer)

\section{Analisa Kapasitas Bundaran}

Nilai kapasitas dasar (Co) dipengaruhi oleh kondisi geometri dari bundaran. Kapasitas dasar dapat diketahui dengan rumus sebagai berikut :

$\mathrm{CO}=135 \times \mathrm{WW}^{1,3} \times\left(1+\mathrm{WE}_{\mathrm{E}} / \mathrm{WW}\right)^{1,5} \times(1-\mathrm{PW} / 3)^{0,5} \mathrm{x}(1+\mathrm{WW} / \mathrm{LW})^{-1,8}$

Kapasitas sesungguhnyabagian jalinan adalah hasilperkalian antarakapasitas dasar (CO)yaitu kapasitas pada kondisi tertentu (ideal) dan faktor penyesuaian (F).

\section{$\mathrm{C}=$ COx FCSx FRSU}

Dari rumus diatas maka besar kapasitas dasar Bundaran Tugu Keris Siginjai yaitu:

a) Jalinan $A B$

$\mathrm{C}_{\mathrm{O}}=135 \times 15,5^{1,3} \mathrm{x}(1+0,56)^{1,5} \mathrm{x}(1-0,09 / 3)^{0,5} \mathrm{x}(1+0,61)^{-1,8}=3877 \mathrm{smp} / \mathrm{jam}$

b) Jalinan BC

$\mathrm{C}_{\mathrm{O}}=135 \times 15,5^{1,3} \mathrm{x}(1+0,56)^{1,5} \times(1-0,18 / 3)^{0,5} \times(1+0,61)^{-1,8}=3817 \mathrm{smp} / \mathrm{jam}$

c) Jalinan CD

$\mathrm{C}_{\mathrm{O}}=135 \times 15,5^{1,3} \mathrm{x}(1+0,56)^{1,5} \mathrm{x}(1-0,141 / 3)^{0,5} \mathrm{x}(1+0,61)^{-1,8}=3843 \mathrm{smp} / \mathrm{jam}$

d) Jalinan DA

$\mathrm{CO}_{\mathrm{O}}=135 \times 15,5^{1,3} \mathrm{x}(1+0,56)^{1,5} \mathrm{x}(1-0,078 / 3)^{0,5} \mathrm{x}(1+0,61)^{-1,8}=3885 \mathrm{smp} / \mathrm{jam}$

Setelah kapasitas dasar diketahui maka dapat diketahui kapasitas sesungguhnya dengan memasukkan fakto FCS dan FRSU, seperti pada tabel berikut:

Tabel 4 Kapasitas Sesungguhnya Masing - Masing Jalinan

\begin{tabular}{ccccc}
\hline Bagian Jalinan & Co (smp/jam) & Fcs & FRsu & C (smp/jam) \\
\hline AB & 3877 & 0,94 & 0,98 & 3571 \\
BC & 3817 & 0,94 & 0,98 & 3516 \\
CD & 3843 & 0,94 & 0,98 & 3540 \\
DA & 3885 & 0,94 & 0,98 & 3579 \\
\hline
\end{tabular}

(Sumber: Analisis Data Primer)

\section{Analisa Derajat Kejenuhan}

Derajat kejenuhan adalah nilai perbandingan antara arus lalu lintas jam puncak atau arus lalu lintas sesungguhnya dengan kapasitas sesungguhnya.

$\mathrm{DS}=\frac{Q}{C}$

Maka derajat kejenuhan pada Bundaran Tugu Keris Siginjai sebagai berikut: 
Tabel 5 Derajat Kejenuhan Masing - Masing Jalinan

\begin{tabular}{cccc}
\hline Bagian Jalinan & $\mathrm{Q}$ (smp/jam) & $\mathrm{C}(\mathrm{smp} / \mathrm{jam})$ & $\mathrm{DS}=\mathrm{Q} / \mathrm{C}$ \\
\hline $\mathrm{AB}$ & 13496 & 3571 & 3,78 \\
$\mathrm{BC}$ & 4943 & 3516 & 1,41 \\
$\mathrm{CD}$ & 8571 & 3540 & 2,42 \\
$\mathrm{DA}$ & 9841 & 3579 & 2,75
\end{tabular}

(Sumber: Analisis Data Primer)

\section{Analisa Tundaan Pada Bagian Jalinan Bundaran}

Tundaan lalu lintas bagian jalinan (DT), menurut MKJI 1997 tundaan lalu lintas ditentukan dari hubungan empiris antara tundaan lalu lintas dan derajat kejenuhan. Perhitungan tundaan bagian jalinan sebagai berikut :

a) Jalinan $\mathrm{AB}$ dengan $\mathrm{DS}=3,78$

DT $=1 /(0,59186-0,52525 \times$ Ds $)-(1-D s) \times 2$

$$
=1 /(0,59186-0,52525 \times 3,78)-(1-3,78) \times 2=0,24 \mathrm{det} / \mathrm{smp}
$$

b) Jalinan AB dengan $\mathrm{DS}=1,41$

$$
\begin{aligned}
\text { DT } & =1 /(0,59186-0,52525 \times \text { Ds })-(1-D s) \times 2 \\
& =1 /(0,59186-0,52525 \times 1,41)-(1-1,41) \times 2=1,49 \operatorname{det} / \mathrm{smp}
\end{aligned}
$$

c) Jalinan AB dengan $\mathrm{DS}=2,42$

$$
\begin{aligned}
\text { DT } & =1 /(0,59186-0,52525 \times \text { Ds })-(1-\mathrm{Ds}) \times 2 \\
& =1 /(0,59186-0,52525 \times 2,42)-(1-2,42) \times 2=0,46 \mathrm{det} / \mathrm{smp}
\end{aligned}
$$

d) Jalinan AB dengan DS $=2.75$

$$
\begin{aligned}
\text { DT } & =1 /(0,59186-0,52525 \times \text { Ds })-(1-D s) \times 2 \\
& =1 /(0,59186-0,52525 \times 2.75)-(1-2.75) \times 2=0,38 \mathrm{det} / \mathrm{smp}
\end{aligned}
$$

\section{Analisa Tundaan Lalu Lintas Bundaran}

Berdasarkan perhitungan sebelumnya diketahui arus masuk bundaran = 36851 smp/jam, maka dapat diketahui perhitungan nilai tundaan lalu lintas bundaran (DTR) sebagai berikut :

a) Jalinan $A B$

$$
\text { Q x DT = } 13496 \times 0,24=3239,04 \text { detik }
$$

b) Jalinan $\mathrm{BC}$

$$
\mathrm{Q} \times \mathrm{DT}=4943 \times 1,49=7365,07 \text { detik }
$$

c) Jalinan CD

$$
\text { Q x DT = } 8571 \times 0,46=3942,66 \text { detik }
$$

d) Jalinan DA

$\mathrm{Q} \times \mathrm{DT}=9841 \times 0,38=3739,58$ detik

$\mathrm{DTR}=\square \square \frac{Q \cdot D T}{\text { Qmasuk }} \square \square \square \square \square$ Qi.Dti $=18286,35$ detik

$\mathrm{DTR}=\frac{18286,35}{36851}=0,49 \mathrm{detik}$

Dari hasil perhitungan nilai tundaan lalu lintas bundaran (DTR), maka dapat diketahui nilai tundaan bundaran (DR) dengan perhitungan sebagai berikut :

$$
\begin{aligned}
\mathrm{DR} & =\mathrm{DTR}+4 \\
& =0,49+4=4,49 \mathrm{det} / \mathrm{smp}
\end{aligned}
$$

\section{Analisa Peluang Antrian Bagian Jalinan Bundaran (Qp\%)}

Peluang antrian pada bagian jalinan bundaran dapat dihitung dengan rumus sebagai berikut :

a) Jalinan AB dengan DS $=3,78$ 
- Batas atas; $\mathrm{QP}=26,65 \times 3,78-5,555 \times 3,78^{2}+108,57 \times 3,78^{3}=5885,25=58,85 \%$

- Batas bawah; $\mathrm{QP}=9,41 \times 3,78+29,967 \times 3,78^{4,619}=13969,64=139,59 \%$

b) Jalinan BC dengan DS $=1,41$

- Batas atas; $\mathrm{QP}=26,65 \times 1,41-5,555 \times 1,41^{2}+108,57 \times 1,41^{3}=330,88=3,30 \%$

- Batas bawah; $\mathrm{QP}=9,41 \times 1,41+29,967 \times 1,41^{4,619}=159,78=1,59 \%$

c) Jalinan CD dengan DS $=2,42$

- Batas atas; $\mathrm{QP}=26,65 \times 2,42-5,555 \times 2,42^{2}+108,57 \times 2,42^{3}=1570,67=15,70 \%$

- Batas bawah; $Q P=9,41 \times 2,42+29,967 \times 2,42^{4,619}=1798,95=17,98 \%$

d) Jalinan DA dengan DS $=2,75$

- Batas atas; $\mathrm{QP}=26,65 \times 2,75-5.555 \times 2,75^{2}+108,57 \times 2,75^{3}=2289,19=22,89 \%$

- Batas bawah; $\mathrm{QP}=9,41 \times 2,75+29,967 \times 2,75^{4,619}=3231,56=32,31 \%$

\section{SIMPULAN}

Berdasarkan analisa penelitian dan pembahasan maka dapat diambil beberapa kesimpulan yaitu sebagai berikut :

1. Dari hasil perhitungan diketahui Tundaan Lalu Lintas Bundaran (DTR) yaitu 0,49 det/smp, dan Tundaan Bundaran (DR) yaitu 4,49 det/smp, maka tundaan Bundaran pada Bundaran Tugu keris Siginjai sama dengan tidak ada karena D $<10$ detik.

2. Dari hasil perhitungan didapat Arus masuk bundaran yaitu $36851 \mathrm{smp} / \mathrm{jam}$ dan Kapasitas sesungguhnya masing - masing jalinan dari yang tertinggi ke terendah adalah :

Jalinan DA = 3579 smp/jamJalinan AB = $3571 \mathrm{smp} / \mathrm{jam}$

Jalinan CD = $3540 \mathrm{smp} / \mathrm{jamJalinan} \mathrm{BC}=3516 \mathrm{smp} / \mathrm{jam}$

\section{Saran}

Dari hasil analisa, pengamatan dan survey lapangan yang telah dilakukan peneliti, maka ada beberapa saran yang ingin peneliti sampaikan yaitu :

1. Agar pemerintah melengkapi rambu - rambu lalu lintas seperti peringatan mengurangi kecepatan kendaraan sebelum masuk Bundaran agar meminimalisir terjadinya kecelakaan lalu lintas dan memperkecil terjadinya tundaan di bundaran akibat desakan kendaraan yang masuk jalinan bundaran.

2. Pemerintah hendaknya menyediakan lahan parkir yang lebih memadai agar kendaraan yang parkir di kawasan Bundaran Tugu keris Siginjai Kota Baru Kota Jambi tidak mengganggu arus lalu lintas.

\section{DAFTAR PUSTAKA}

Anwar Rosehan. 2012. Analisa Bundaran Pada Simpang Empat Jalan A. Yani Km 36 Banjarbaru (Jurnal). Banjarmasin: Fakultas Teknik Unlam Banjarmasin.

Badan Pusat Statistik Kota Jambi,2017. Jambi Dalam Angka Tahun 2017. BPS Kota Jambi.

Khisty, C.J, B. kent Lall (2005), Dasar-dasar Rekayasa Transportasi/edisi ke3/Jilid I. Jakarta : Erlangga.

Manual Kapasitas Jalan Indonesia (MKJI) 1997. Direktorat Jendral Bina Marga. Jakarta.

Sukirman silvia, (1999), Dasar-dasar Perencanaan Geometrik Jalan. Bandung : Penerbit Nova. 
Sumina. 2008. Analisis Simpang Tak Bersinyal Dengan Bundaran (Jurnal). Surakarta: Fakultas Teknik Tunas Pembangunan Surakarta. 